\title{
The impractical supremacy of local identity on the worthless soils of Mappano
}

\author{
Paolo Pileri ${ }^{1}$ and Riccardo Scalenghe $2^{2^{*}}$
}

\begin{abstract}
Introduction: Soil is under pressure worldwide. In Italy, in the last two decades, land consumption has reached an average rate of $8 \mathrm{~m}^{2}$, demonstrating the failure of urban planning in controlling these phenomena. Despite the renewed recognition of the central role of soil resources, which has triggered numerous initiatives and actions, soil resources are still seen as a second-tier priority. No governance body exists to coordinate initiatives to ensure that soils are appropriately represented in decision-making processes. Global Soil Partnership draws our attention to the need for coordination to avoid fragmentation of efforts and wastage of resources. Both at a global and at a local level, the area of fertile soils is limited and is increasingly under pressure by competing land uses for settlement, infrastructure, raw materials extraction, agriculture, and forestry.
\end{abstract}

Discussion and Evaluation: Here, we show that an administrative event, such as the creation of a new small municipality, can take place without any consideration of land and soil risks. This is particularly problematic in the Italian context as recent studies demonstrate that increasing local power in land use decisions coupled with weak control by the central administration and the high fragmentation and small dimension of municipalities has boosted land consumption. The fragmentation of municipalities has been detrimental to land conservation.

Case description: The case study of Mappano (in the northwestern Italian region of Piedmont on the periphery of the regional capital city of Turin) is emblematic to demonstrate the role played by the supremacy of local identity or local interests despite the acknowledged importance of the key role played by soil everywhere. The contradiction highlighted by this case raises discussion amid some crucial issues as to the role of local urban planning and the protection of soil, which cannot be fragmented or subject to local short-term visions/interests.

Conclusions: In this perspective, urban planning has to address soil and land issues by introducing new rules and competences at the local level and beyond.

Keywords: Urban sprinkling, Europe, sprawl, Land development, Soil protection

\section{Background}

The deterioration of the natural environment is today perceived as a serious problem and our self-reliance on unlimited technological development has declined. Many natural commodities deserve attention because they are finite. This is the case for soil: soil absorbs and filters rainwater; enables the safe decomposition of waste; provides raw materials such as clay, sand, and gravel; sustains infrastructures; conserves archaeological and other cultural remains; and is a key reserve of biodiversity. Soil underpins

\footnotetext{
*Correspondence: riccardo.scalenghe@unipa.it

2 Università degli Studi di Palermo, Palermo, Italy

Full list of author information is available at the end of the article
}

almost all food production, and is becoming evermore precious due to increasing human pressure (Gerland et al. 2014; Salvati 2015). Among the causes of degradation of soil, water and air resources (Haase and Nuissl 2007; Scalenghe and Ajmone Marsan 2009; Yang and Lo 2002; Vaz and Nijkamp 2014) in both developed and developing countries, urban sprawl is seen as responsible for social exclusion (Power 2001), increasing social costs (Burchell et al. 2002; Deal and Schunk 2004), and a threat to public health (Wells et al. 2007). Urban sprawl, due to its low densities, is clearly inefficient as it regards land and soil use. Members of so-called "more primitive" societies, when observing a surface soil layer, distinguish between soil 
strata according to colour and texture, how easily they can be worked, and the best match between soil and crop type (Dubiez et al. 2014). Normally, in these societies, people are aware of changes in the surface layers of soils that are due to anthropogenic activities or environmental changes. Members of the most developed societies have a perception of soil that is limited to its direct effects on human health (Kim et al. 2014; Quansah et al. 2001; Vandermoere 2006); the perception of soil is the perception of risk rather than the potential of the soil itself (Vandermoere 2008).

Furthermore, as the world becomes more globalized and interlinked, the theoretically homogenizing effects of globalization have produced an extraordinary shift in the opposite direction (Schnell 2013). And although local choices were key driving factors of soil and landscape management at a wider scale, as implicit costs in transforming any single hectare of soil affect a much larger group of people than those who authorized the transformation (Malucelli et al. 2014), the supremacy of the local identity is counterintuitively the main driver of social actions in more developed countries. This is a small case study involving a few thousand citizens. In it, there is an open social and institutional conflict with soil at the centre of the debate. The intrinsic characteristics of the soil itself are unknown to all parties involved.

\section{Mappano as a case study}

Until the time of the referendum in 2012 there was no official, unique or shared definition of what is the

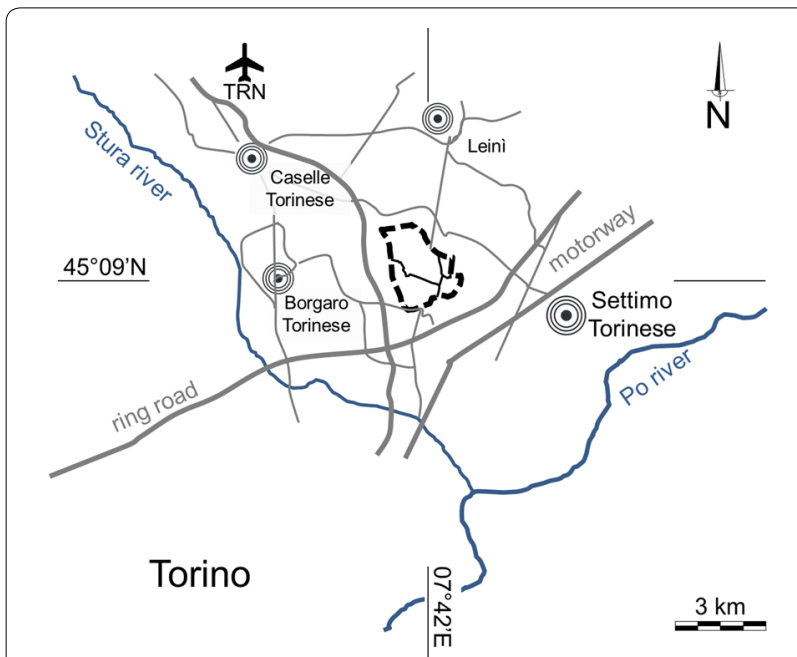

Fig. 1 The area highlighted by the black dotted line in the middle of the figure is Mappano. Boundaries of the City of Mappano, the establishment of which was matter of a referendum on 11 November 2012 (Council of the Piemonte Region, DCR 180-29,152/2012, July 17). The inner lines represent the portions of the territory pertaining to the municipalities of Settimo Torinese, Leinì, Caselle Torinese and Borgaro Torinese respectively territory of Mappano, a conurbation that extends over the territory of the municipalities of Borgaro Torinese, Caselle Torinese, Leinì, Settimo Torinese, and Torino $\left(45^{\circ} 08^{\prime} 54^{\prime \prime} \mathrm{N} 07^{\circ} 42^{\prime} 28^{\prime \prime} \mathrm{E}\right.$, Fig. 1). Nevertheless, there is a longstanding and firm perception of the 'mappanese' territory professed by inhabitants and those living in neighbouring communities. Most of the commercial activities of the area refer to the name Mappano and not that of the proper municipality, both in signs and in documents filed with the Chamber of Commerce of Turin. Mappano experienced strong demographic and economic growth in line with other municipalities in northwestern Italy participating in the broader process of suburbanization of the City of Torino during the 1980s. The availability of large open areas allowed for the programming of important land conservation linked to the creation of a large local and broader regional park that extends from the towns of Borgaro and Settimo and is part of the larger project of the 'Green Crown' of the metropolitan area of Torino. Contemporaneously, various interventions for the completion of infrastructure and the rearrangement of urban areas were programmed. This area is located nearby to the strategic infrastructures serving the entire metropolitan area of Torino (Fig. 1): the A4 motorway (with the relevant section of the ring road), Pertini airport of Caselle Torinese, the high-speed railway to Milan, and the Canavesana railway line of the metropolitan rail system. In addition, the construction of line 2 of the Turin subway out to Settimo Torinese and the upgrading of the Torino-Ceres railway line connecting the airport to Torino's city centre are planned.

\section{Historic contextualisation}

Permanent settlements (from the thirteenth century) in Mappano depicted this area as the swamp of Caselle because of the properties of its soils (De Matteis and Ferlaino 2003). In the fifteenth century, Antonio de Amapano (from whom possibly originates the name "Mappano") began to reclaim the territory, constructing farms in which, among other crops, rice was cultivated. In the sixteenth century, further human intervention on the landscape was undertaken with the construction of a net of irrigation canals. During the nineteenth century, the presence of drainage channels and large open spaces in the area attracted many families of washers, an activity that characterises the suburbs of Turin. The first church in Mappano was built in 1850 . The settlement, in that period, consisted of a group of farms scattered along the road between Turin and Leinì that did not expand significantly during the boom after the Second World War. In the 1970s, the Turin metropolitan area experienced a rapid increase in the population in the belt formed by the municipalities of the metropolitan area most distant 
from the centre of Turin. The first belt, which had already grown enormously, slowed its growth in the same period.

In a good geographical location, not far from the main city and close to major axes and connection points (the Turin-Milan motorway, the ring motorway, and the airport), the 'mappanese' territory developed during the 1980 s in a fairly concentrated way around a traditional core. Mappano extends mainly in the municipalities of Caselle Torinese and Borgaro Torinese, respectively 60 and $30 \%$ of its residents in 2001. As we shall see, Mappano is ideally located for the installation of residential and administrative activities of the municipalities in the Turin basin (especially Borgaro and Caselle), since they exist in a suburban area close to thoroughfares with a central core around which to focus the planning of residential and productive activities, as provided by the instruments of land regulation in force. In Mappano, most of the houses were built in the decade between 1961 and 1971 with a significant recovery of the buildings from 1981 onwards. The dynamics here are similar to those of Borgaro, where there is a drop in construction between 1971 and 1981 that then resumed in correspondence with the significant increase of the population in the decade from 1981 to 1991 . Units with 16-30 or more than 30 homes increased substantially in the period between 1981 and 1991. The majority of housing is owner-occupied by individuals.

In 1992, a referendum for the unification of the scattered territory of Mappano within a single municipality began the formal statement of the principle of identity. The municipalities of Borgaro Torinese, Caselle Torinese, Leinì and Settimo Torinese deliberated over a "restricted 'mappanese' area" (5.5 km² and 6427 inhabitants in 2001). The City of Turin did not produce any resolution. The Committee for the Establishment of Mappano identified instead an enlarged area, $10.5 \mathrm{~km}^{2}$ (7080 inhabitants in 2001). Comparing the two areas, major changes occur in the number and extent of farms and the number of farm employees (the latter mainly related to the inclusion, or not, of the district of Fornacino, which was disputed between Leinì and Settimo Torinese).
To read properly the evolutionary dynamics of the 'mappanese', a useful comparison is with the largest metropolitan basin where the aggregate of the municipalities within which we can locate the area of Mappano: the Conferenza Metropolitana di Torino, CoMeTo (established by Piemonte Regional Laws 142/1990 and 265/2000) (De Matteis and Ferlaino 2003). The supramunicipal entity CoMeTo, 38 municipalities of the metropolitan area of Torino, increased in population by $6 \%$ during the 1980s, although less than in the previous decade (14\%): managers, professionals, employees and entrepreneurs are present to a greater extent in the main City of Torino while workers and self-employed showed a greater tendency to reside in the north and south suburban area of Turin with a massive industrial development (Ferlaino et al. 1994).

During the 1980s, in all municipalities of the administrative basin of Mappano the population grew similarly to that of the metropolitan area of Torino participating in the broader process of suburbanization. Borgaro, Caselle and Settimo grew much in terms of population between 1981 and 1991, confirming this trend in the census of 2001 (Table 1).

An economy based on manufacturing firms and service to large-scale industry has prevailed in the northwestern part of the metropolitan area (Fig. 2). This is particularly evident when considering the prevailing professions (workers and employees) and the areas in which they are used (industry and recently the tertiary sector), while taking into account the trend towards outsourcing of the entire metropolitan area. The categories of firms in Mappano were (2003 data) woodworking industries, processing industries, non-metallic mineral factories, manufacturing industries of computers and office machinery, manufacturing industries of medical devices, manufacture of other transport equipment (excluding cars), and other services. Housing capital has increased considerably during the end of the 1990s, especially for Settimo, Borgaro and Caselle, less for Leinì, in line with the values of CoMeTo (Table 1). During that period, the total taxable income grew consistently in Borgaro, Settimo and Leinì

Table 1 Area, population, population density, from municipal to the metropolitan (1981)

\begin{tabular}{|c|c|c|c|c|c|c|}
\hline & $\mathrm{km}^{2}$ & Census 1981 & Census 2001 & Census 2011 & Persons km ${ }^{-2}$ (2001) & $\begin{array}{l}\text { Housing } \\
\text { value }^{\mathrm{a}}\left(10^{6} €\right)\end{array}$ \\
\hline Cometo & 859 & 1.701 .141 & 1.537 .079 & & 1.789 & 18 \\
\hline Cometo (without Torino) & 729 & 583.987 & 637.787 & & 875 & 27 \\
\hline Borgaro Torinese & 14 & 8.548 & 12.754 & 13.502 & 888 & 28 \\
\hline Caselle Torinese & 29 & 12.463 & 15.851 & 18.635 & 552 & 27 \\
\hline Leinì & 32 & 13.740 & 11.942 & 15.523 & 368 & 17 \\
\hline Settimo Torinese & 32 & 44.210 & 46.982 & 48.036 & 1.452 & 34 \\
\hline
\end{tabular}

a 1996-1999 data from De Matteis and Ferlaino (2003) 


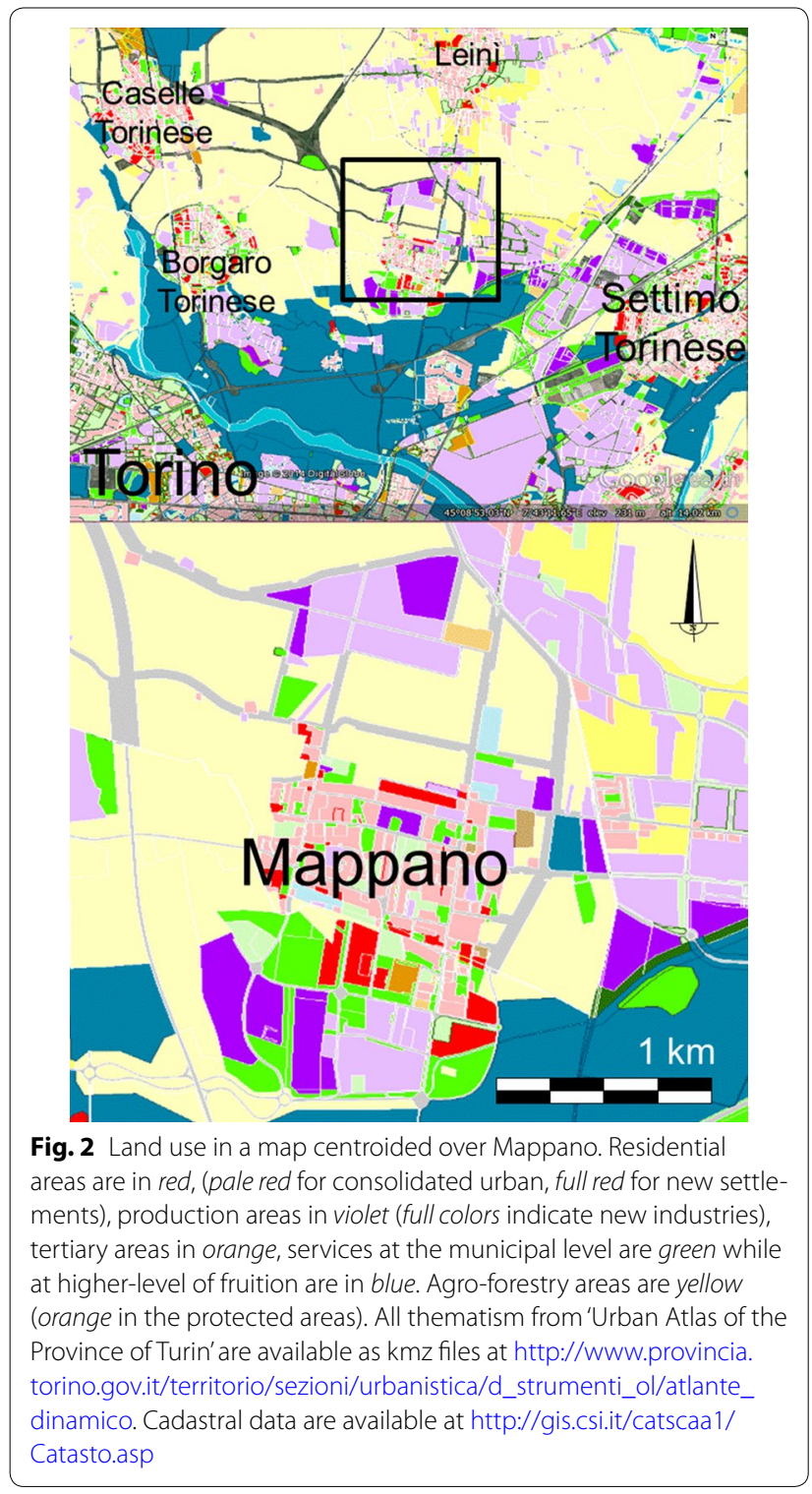

(83, 72, and $67 \%$ respectively), compared to $56 \%$ at Settimo and $44 \%$ of CoMeTo; the average taxable income per capita grows instead in a similar manner in all the municipalities in the metropolitan area and, to a greater extent, in Leinì (De Matteis and Ferlaino 2003). The transfer of public tax to the municipalities in the period 1996-2002, compared with an increase of $4 \%$ in CoMeTo without Torino, an increase of $43 \%$ in Borgaro, $31 \%$ in Caselle of $18 \%$ in Leinì and only $2 \%$ in Settimo (the transfer per capita was $30 \%$ in Borgaro, $26 \%$ in Caselle, $21 \%$ in Leinì and $7 \%$ in Settimo) (De Matteis and Ferlaino 2003).

\section{Planning}

The zoning planned for the area of the four municipalities in the administrative basin of Mappano has been adopted and approved in the last decades without any explicit intent of coordination (Fig. 3). In Caselle Torinese (Piano Regolatore Generale Comunale, PRGC, 22/01/2001), the prevalent use of the soil, excluding agriculture, is planned for small residential areas of expansion. In addition to the residential areas, agricultural areas are foreseen in the planning. Envisaged is the realization of a multi-purpose residential area. The realization of some residential health and recreational services is also planned. In addition to the existing cemetery located northwest of the town of Caselle Torinese, PRGC projects the construction of a cemetery on the extreme outer edge of the municipal area, immediately next to the municipal boundaries of Settimo Torinese and Borgaro Torinese.

To the north of the planned town there is a large production area established, around which there are areas of completion, and an area of the tertiary sector consolidated near the border of Leinì. In general, we can observe a compact town and a classification of production areas and services that tends to maintain the character of the compactness. In Borgaro (PRGC 21/02/1994 and following eight modifications) there are large areas of production, service areas/plants and a few residential buildings. There is also a large residential area of expansion into the industrial zones. The rest of the land is for agricultural purposes except for a small production area (partially completed) and an equally small residential area near the border of Turin. Leinì (PRGC 21/02/2000 and following fifteen modifications) forecasted a much lower extension of agricultural land. In the area of Turin that is considered a part of the "mappanese territory," there are small service areas. Settimo (PRGC 07/10/1991 and following 32 modifications) is almost entirely agricultural, with the exception of a few consolidated production areas on the border of Leinì in the frazione of Fornacino. There is also a small residential area in this zone. The territory of Leinì on the border of Caselle has a residential area that is traditionally part of Mappano, with production areas in large part consolidated up to Fornacino, which are again at present residential areas. In the report of the PRGC of Settimo Torinese, the word 'Mappano' is mentioned only once and there is no specific map attached.

There are agencies that have jurisdiction over the entire territory, as with the case of waste disposal, water services, security, and justice, the whole area is considered a single territory. So it is with the prefecture, the police, the fire department, the criminal judiciary, the public prosecutor. Justices of the Peace, the sub-offices of the District Court, prosecutors, and the local Catholic diocese all consider the Mappano area as an extension of Turin. A project called "PRUSST 2010 plan" envisaged investments of around 500 million EUR, of which approximately two-thirds are private and the rest public. 


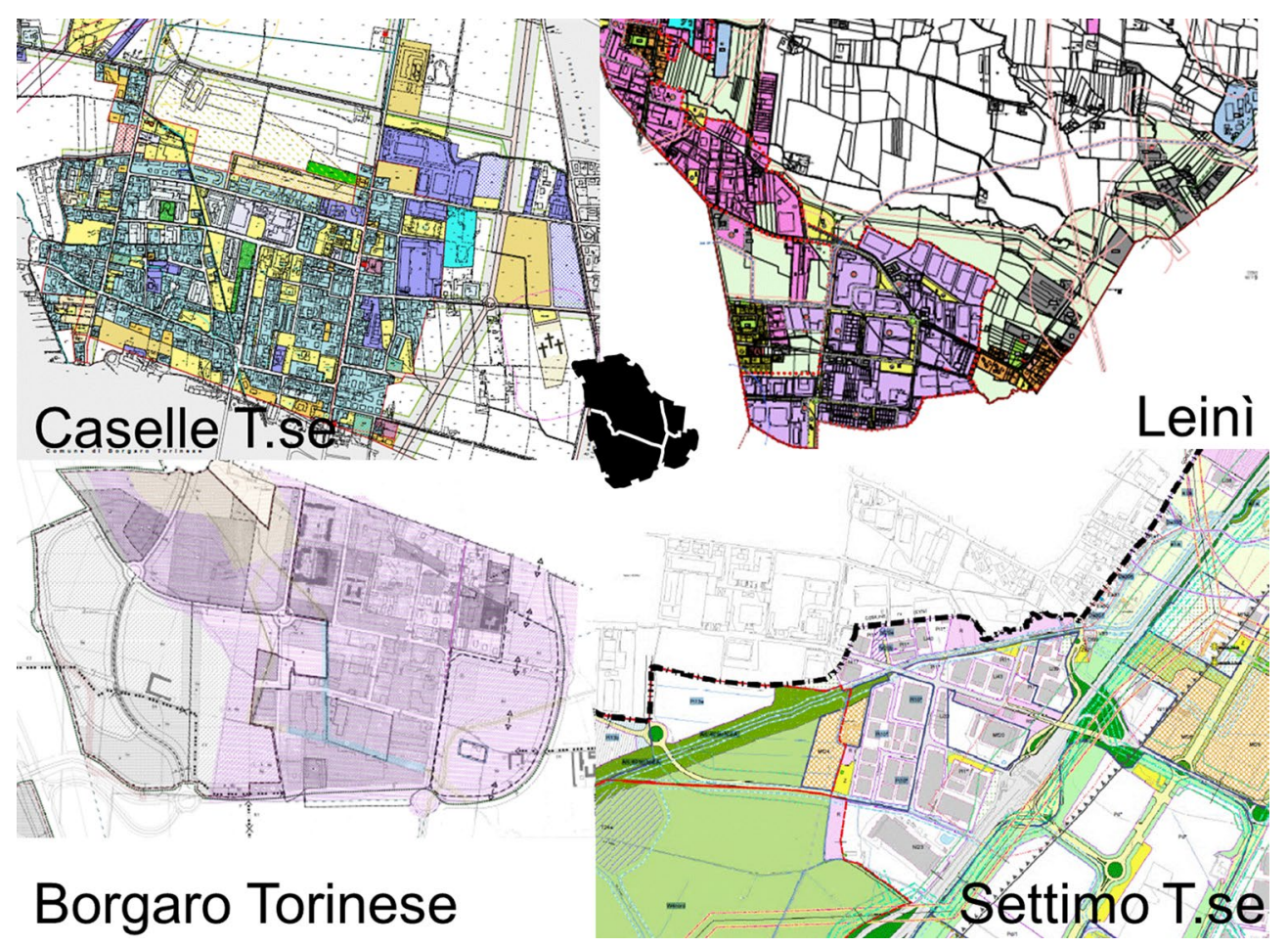

Fig. 3 The spatial planning of the four municipalities on the area of specific relevance in the territory of the district of Mappano: the Piano Regolatore Generale Comunale (acronym PRGC) of Settimo Torinese (20.03.2014 modification), Leinì (01.10.2011 modification), Caselle Torinese (01.03.2007 modification), and Borgaro Torinese (29.01.2013 modification). URLs of existing official planning are respectively: Settimo Torinese http:// www.comune.settimo-torinese.to.it/index.php?option=com_zoo\&task=item\&item_id=2545\&ltemid=246\&lang=it, Borgaro Torinese http://www. comune.borgaro-torinese.to.it/interna.asp?.pag=22, Caselle Torinese http://www.gis2000.eu/comunecaselletorinese/tavole_prg.htm, and Leinì http://www.comune.leini.to.it/PaginedelComune/tabid/3288/Default.aspx?lD=59. All these areas have been merged at provincial level and kmz files are available at http://www.provincia.torino.gov.t/territorio/sezioni/urbanistica/d_strumenti_ol/atlante_dinamico

PRUSST was prepared by the municipality of Settimo Torinese in agreement with the municipalities of Torino, Brandizzo, and Borgaro Torinese planning a connection and completion of the Green Crown creating an interconnected park between urban parks (in Borgaro and Turin) and regional parks (La Mandria Park and the Po River) to form a corridor. The plan for the area of BorSetTo (from the names of the signatory municipalities) is another similar intervention of inter-institutional cooperation and coordination. BorSetTo involves approximately 3 million square meters to be used as public park, residential areas and services ( $12 \%$ of the total area), and a technology center in the Mappano area belonging to Borgaro Torinese.

The municipalities of Borgaro Torinese, Caselle Torinese, Settimo Torinese jointly with San Benigno, San Mauro Torinese and Volpiano (URL http://www. unionenet.it) since 2011 have formed the Union of Municipalities of North-East Turin (since 2015, the Municipality of Leinì adhered to the Union NET, bringing the total number of the union itself to seven). Union
NET has as its primary objective the associated management and coordinated community services for an increased usability according to the principles of simplification and cost containment.

\section{Soils}

Land capability classification (LCC) categorises, in general, the suitability of soils for (field) crops, grouping soils according to their limitations, the risk of damage, and the way they respond to management. The criteria used in grouping the soils do not include major and generally expensive landforming that would change slope, depth, or other characteristics of the soils, nor do they include possible but unlikely major reclamation projects (Fig. 4). All the municipalities of the area contain a variety of LCC classes from soils that have slight limitations that restrict their use (Class 1) to soils subjected to little or no erosion but without other limitations (Class 5). The 'mappanese' territory contains only soils with severe limitations that restrict the choice of plants, require special conservation practices, or both (Class 3$)$. 


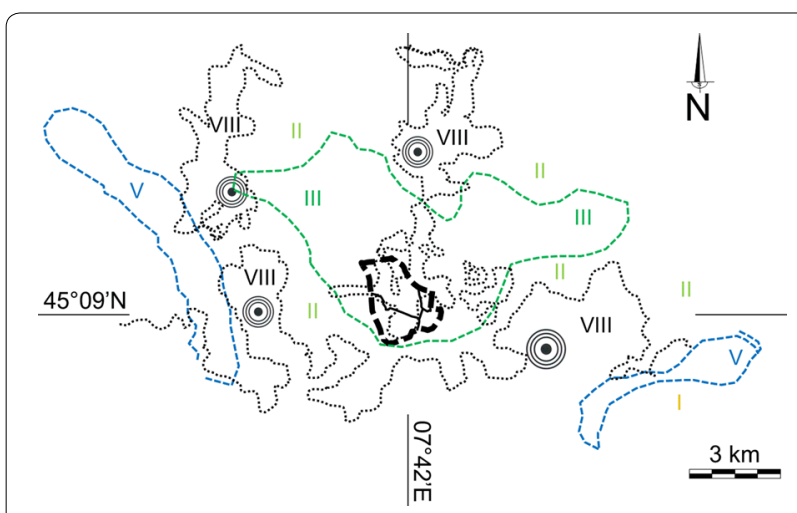

Fig. 4 Roman numbers indicate the classes of land capability classifcation (LCC), which depend on soil limitations to various uses (source Regione Piemonte). LCC classes indicate progressively greater limitations and narrower choices for practical use. Class I (orange) does not have any limitation to crops, class II (pale green) shows moderate while class III (dark green) severe limitations that require special conservation practices. Class $V$ (blue), because of topography, stoniness and erosion, could not be used for even occasional cultivation. Class VIII (black), does not produce vegetation for any agricultural use. The dotted area outlined in the middle of the figure is Mappano

\section{Institutional activity}

In December 2002, the Region of Piedmont, in implementing agenda n. 556 of 18 June 2002 of the Regional Council, entrusted IRES (Institute for Economic and Social Research, Piedmont) with the task of conducting a study about the size of the territory, its population, and its optimal economic and social structures, assuming the institution of the new municipality of Mappano or other administrative solutions would meet the needs of a reorganized "mappanese" territory. This need arises from the difficulty of governing a frazione divided among five municipalities (Borgaro Torinese, Caselle Torinese, Leinì, Settimo Torinese, Turin) as well as the difficulties in organizing daily activities and services for the inhabitants of Mappano. A partial response to the needs of the 'mappanesi' came with the establishment of MappanoCIM (Consorzio Intercomunale Mappano) by three municipalities of the common area (Borgaro Torinese, Caselle Torinese, and Leini). Interviews with the mayors of the municipalities in the basin administration in 2002 (De Matteis and Ferlaino 2003) revealed a need for joint planning of the territory and greater protection (e.g., through the recent request to create a codified regional rather than inter-city park in order to protect it from any political changes of mind within individual municipalities). The hypothesis of the amalgamation of Mappano is favored by the mayors of municipalities in the administrative basin despite the 1992 referendum not being accepted. The merger of municipalities is an institution governed by law 142/1990 and art. 15 of Legislative
Decree no. N. 267/2000, which provides that two or more contiguous municipalities can be merged (this concept has been taken into account and enforced by law $n$. $56 / 2014)$. This hypothesis has been considered only by the Mayor of Leinì, in our interview, as a hypothesis viable in the long term to coordinate comprehensively the different activities of the municipalities in the administrative basin of Mappano. At the moment, however, the hypothesis seems less likely.

There are seven different assumptions guiding the political-institutional debate: (1) the consortium, (2) the merger, (3) the incorporation of a single municipality, (4) the establishment of a new municipality, (5) the union of municipalities, (6) of the Convention, (7) or simply maintaining the status quo. These various hypotheses have different probabilities of success and offer different opportunities. The consortium is a functional tool, more and more oriented to the management of efficient "public market" services and, as the crisis of the CIM, less and less able to respond to the needs of nature and identity. The fusion of the municipalities making up Mappano is a legislatively viable hypothesis, but requires a socio-economic identity of the whole basin, as well as a common desire among institutional constituents, which, according to contemporary analyses, currently exists. The incorporation of a municipality is an institutionally viable hypothesis', but one burdened by the negative outcome of the previous referendum and still feeling the detrimental historical identity of a not inconsiderable part of the local population. It could then respond to functional needs but at the expense of identity. The establishment of a new municipality is certainly the tool that best answers the question of identity locally, but is subject to two major obstacles: in accordance with current regulations it was not feasible in the short to medium term due to a lack of population (7080 residents in place of the 10,000 once requested) and also different visions of space identity, which are scarcely shared within the proposal. The union is a common way forward, even if in a rather unusual and original way, as there seems to be a marriage made in Italy to meet the needs of sub-regional municipalities: Originality of the path in the form of regional subsidies, and ability to define an institutional model largely to be built to meet the identity of Mappano and the functional requirements of its basin. The convention is an instrument that quite possibly fulfils the functional requirements and also identity. It is a solution that would use previous experience, because it appears to be the nearest "legal translation" of the instrument of a reformed consortium. Finally, the "status quo" is also mentioned as a likely scenario because it can avoid the set-up costs of any instrument and the emergence of conflicts and latent needs. In January of 2013 interviews were carried out 
with the mayors of the municipalities in the administrative basin of Mappano, the chairman of the Committee for the Establishment of a Common Mappano and the President of the Municipality.

\section{Interviews}

In January 2013, we interviewed a few people who, from our point of view, could summarize the key facts in the 'Mappano' story.

Francesco Grassi (President of the Mappano Committee since 2007) said that «The current situation does not work because it was imposed from above. Union will not become fusion [and] physical proximity between citizens and administrators is very important. The region has delegated the final decision directly to the citizens.» The soil capability of the territory of Mappano is unknown to him.

Luca Baracco (Mayor of Caselle Torinese) said that «The costs will be paid by the citizens [and] the municipality of Caselle risks financial distress. In addition, reducing the number of inhabitants' instability becomes an administrative burden. In the referendum of 2012, the 'yes' side formally won although voter turnout amounted to less than $10 \%$ of those who had the right to vote. The Region of Piedmont initially proposed funding the creation of the new municipality of Mappano with 100,000 EUR and to reward the neighboring municipalities with 30,000 EUR each. I suppose that the costs to create the new municipality will be paid directly by all its citizens. My town will drop to 14,000 inhabitants, which will have a practical significance and symbolic meaning: there is a real risk of financial collapse. Dissemination has not been made at all by the provincial and regional stakeholders.» Land capabilities of the territories of Caselle Torinese and Mappano are unknown to him.

Vincenzo Barrea (Mayor of Borgaro Torinese) said that «Mappano represents the paradigm of the overall situation of Italy today. The area of Mappano has only recently been reclaimed as it previously was mainly marshes. Administrative problems that prompted the creation of the Committee for the City of Mappano were almost all resolved with the Consorzio Intercomunale that has worked for several years. The main need for Mappano as an independent town is genuine but it is anti-historical. To self-finance the new municipality the new town will have to practice a dissipative land planning. I see favourably the union of municipalities preserving the identity of their citizens.» Land capabilities of the territories of Borgaro Torinese and Mappano are unknown to him.

Aldo Corgiat (Mayor of Settimo Torinese) said that «The citizens of my town are against losing territory in favour of citizens who are not from Settimo Torinese but, who, in reality are from Caselle Torinese. The referendum (paid for by all citizens of Piemonte) was a cross-party decision. Initially, my proposal was to simulate a hypothetical but accurate budget and plan for the new city, but no one accepted this idea. A confinement basin was planned for an area of over $900,000 \mathrm{~m}^{2}$ adjacent to the tributaries of rivers to protect Settimo Torinese from flooding and downstream erosion by storing water for a limited period of time. The maintenance of this area for years was paid by the municipality of Settimo Torinese at a cost of some 4 million EUR to the community. This area is one that would be gained from the new town, which has no formal requirement for maintenance ${ }^{1}$. That one is the only area for new potential development». Land capabilities of the territories of Settimo Torinese and Mappano are unknown to him.

Leinì Town Council was closed down due to mafia infiltration by the Ndrangheta calabrese since 23-03-2012. Rita Piermatti (Special Commissioner of Leinì ex arts. 143-144 d.lgs. 267/2000) has not been interviewed.

\section{Discussion}

In major Italian cities, the population dynamics of the last decades describe, between 1951 and 2010, a general reduction of the residents within the city $(25 \%$ average decrease) that is opposed to an increase of about $10 \%$ among the first and the second urban belts (source ISTAT).

Local land use decisions are frequently in the hands of individuals who lack formal training in planning (Kaplan et al. 2008). If one considers Mappano from the viewpoint of land consumption (Table 2), the case reveals serious new concerns having to do with the vulnerability of our landscape culture. A survey in a similar context showed that the smaller the municipality, the larger the area of farmland (agricultural soil) sealed per newcomer inhabitant (Fig. 5). It is important to note that land consumption in Italy is very high: $8 \mathrm{~m}^{2} / \mathrm{sec}$ (70 ha/day) are sealed (Munafò et al. 2013) and no law has been passed yet to protect soils and lands. In the 21 Member States of the European Union, the land taken from agriculture was calculated to be 752,973 ha for $1990-2000$ and 436,095 ha for 2000-2006 (Gardi et al. 2014).

One of the subjects of this paper deals with the acknowledged impacts of the decision to create a new micro municipality as a spin-off of existing and larger ones, on the environmental/landscape matrix, in which soil or land is an emblematic issue.

\footnotetext{
${ }^{1}$ At the moment (2016, 2nd of May) this is the unique controversial formal issue that has stopped the election of the new Mappano's Major. It is no coincidence that the element that is stopping the process is an environmental matter. This requires a different vision, not conceivable with the rigidness of administrative competences. So the administrative fragmentation, a new formal stakeholder together with its new demands and the re-design of the boundaries without any formal coordination are a problem, not a solution.
} 
Table 2 Consumption of soil in the municipalities where the new municipality of Mappano is to become independent. Data in $\mathbf{~ k m}^{2}$

\begin{tabular}{lcccrr}
\hline & $\mathbf{k m}^{\mathbf{2}}$ & $\mathbf{U L T}^{\mathbf{a}, \mathbf{b}}$ & $\mathbf{I L T}^{\mathbf{a}, \mathbf{b}}$ & $\mathbf{R L T}^{\mathbf{a}, \mathbf{b}}$ & $\mathbf{T L T}^{\mathbf{a}, \mathbf{b}}$ \\
\hline Torino & 130 & 71.37 & 4.97 & 2.10 & 78.44 \\
Borgaro Torinese & 14 & 2.78 & 0.36 & 0.14 & 3.28 \\
Caselle Torinese & 29 & 4.99 & 0.64 & 0.03 & 5.66 \\
Leini & 32 & 5.88 & 0.51 & 0.06 & 6.45 \\
Settimo Torinese & 32 & 8.67 & 1.34 & 0.05 & 1.55 \\
\hline
\end{tabular}

a Data from Finotto and Paludi (2012), Provincia Torino (2012)

b ULT land used by urbanized area, ILT land used by infrastructure, RLT reversible land use, TLT overall land use

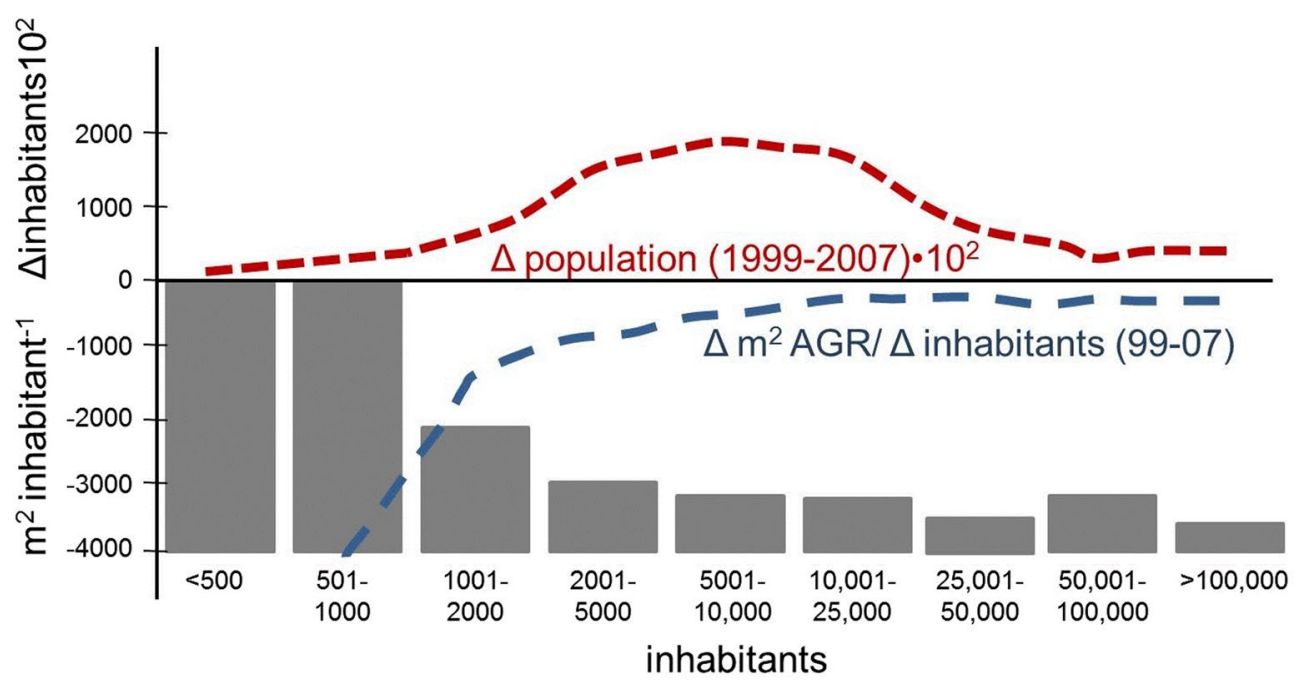

Fig. 5 Consumption of farmland areas (AGR) per new inhabitant in Lombardy Region, Italy (1999-2007). Data ranked by demographic classes of individual municipality (histograms) according to Di Simine et al. (2013)

To clarify the use of terms, we call 'administrative fragmentation' both the high number of institutional policy makers that decide on environmental and social issues on the territory and the increase in the number of smaller decision makers. In this way, several units govern the landscape, each maximising its own goal on a small territory with an added need for inter-agency dialogue and coordination.

From the land consumption point of view, fragmentation is a serious menace as it is a process that separates and divides the continuity of the landscape. We cannot forget the available data illustrating that in small towns, the most common type of residence is the single-family home that continues to survive because of its perverse symbiosis with the private car, which in turn paradoxically survives only by consuming non-renewable energy resources such as petrol and diesel.

Besides, focusing on soil, data in Fig. 4 remind us that if one municipality splits into two smaller ones with fewer inhabitants, the risk of consuming more land per new inhabitant is higher than before. This is due also to the Italian peculiarity where a part of local taxes arises from the decision of municipalities to transform a piece of non-urbanized land into an urbanized one. Since 2004, many municipalities in Italy no longer receive money (or receive very little) from Rome or their home regions to pay for local services. So the possibility to use local taxes from urbanization has become an option more and more affordable to attract new inhabitants hoping they will contribute to the local economy and gather more money from urban developers.

This is a high risk for cases like Mappano. During the interview with the leader of the movement 'Creating Mappano', he clearly stated that an amount of money to develop local services for citizens could have arisen from taxes paid by future developers invited to transform agricultural areas into urban ones.

Municipalities in Italy decide autonomously on land use changes and the control by regions has become weaker and weaker during recent years. 
This scenario seems to be more problematic if we recognize that $28 \%$ of Italy territory is governed by municipalities of under two-thousand inhabitants (equal to $43 \%$ of Italian municipalities) and $70 \%$ of all Italian municipalities have less than 5000 inhabitants. The latter administrate more than half the nation's territory suggesting to us that the effects of this spatial-population distortion are severe and widespread.

Land dissipation is extremely difficult to manage because it has become culturally engrained in local politics, administration, and popular belief. Therefore, according to this popular notion, everyone is expected to partake in the worship of ground rent. This vulnerability is expected to be higher in small municipalities where there is more likely to exist political-administrative parochialism. This study in absurdity creates the perfect conditions in which sooner or later every family and/or interest group is able not only to possess but also to govern its own land in the most self-advantageous of ways (Pileri and Granata 2012). This is not just a tax issue, then, but rather a much broader problem concerning the administrative and territorial structures in which tax and urban policy are found (Pileri 2015).

To all this is added a cultural habit that feeds into the atavistic insensibility towards the environment and landscape, into a certain lifestyle based on the ridiculous notion that energy resources are inexhaustible and into a near total irresponsibility towards the production of food.

Mappano was born in this negative situation premised on new land consumption and a culture where the ecological value of soil is not taken into consideration. The consequences for landscape and soil of new urban development has not been represented in either the political or popular discourse.

Mappano is paradigmatic of many situations in Europe. The local decision makers do not know their soils that, among other problems, suffer of high concentrations of heavy metals due to unfavorable combination of infrastructure and heavy traffic (e.g., Scalenghe and Fasciani 2008). Further reason to imagine taking care of the state of the soil systematically and not fragmentary, following a logic trivialized by making profit above all. Futhermore, the spirit of local identity, especially in recent years, evokes the agricultural vocation of the territory of Mappano (Fig. 6) without taking any account of the fact that soils, from the point of view of their agronomic potential, are the worst within the whole agricultural area (Fig. 4). In developing countries, social learning normally encourages the emergence of a positive attitude about the adoption of soil conservation innovation (Dessie et al. 2013) but in more economically developed countries, soil degradation and other land concerns require immediate

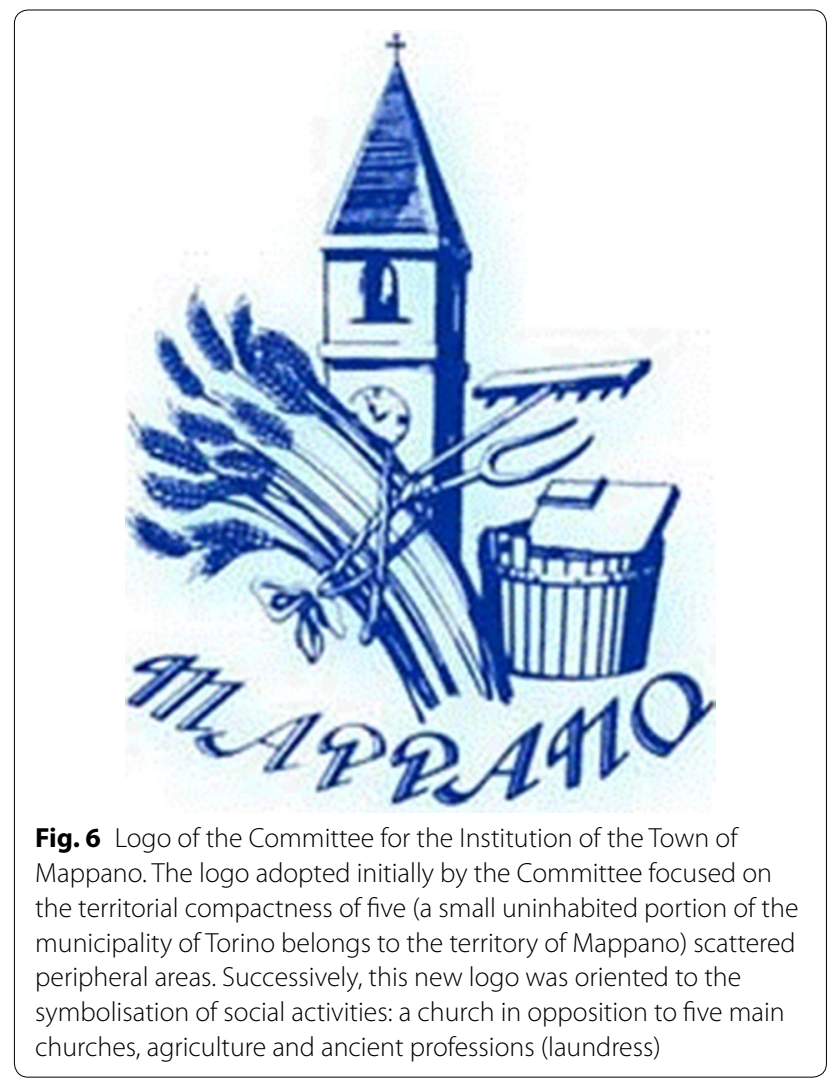

policy attention informed and underpinned by rigorous technical knowledge (Thomas et al. 2012). Then, several policy strategies could be pursued, for instance economic instruments providing incentives for compliance with regulatory norms (the monetary benefit for landowners to whom land development permission has been granted through zoning could be then recaptured by tax yields) (Nuissl and Schroeter-Schlaack 2009).

The term 'identity' sometimes criticized for its intrinsic indefinability and ambiguity (Bray 2002; Brubaker and Cooper 2000) is important to describe how local political actors identify themselves with a given territory (Del Biaggio 2014; Desouza and Flanery 2013; Häkli 2001). In our case study, the struggle for a recognised 'Mappanese' identity is stronger than the awareness of the value of environmental resources with which the population lives, in particular the value of the soil resource. It is far the attempt to initiate bottom-up activities by showing specific advantages of improving soil quality proposed by Bouma and Droogers (2007). Could be decisive the use of social learning with associated investment? Social learning has in fact major implications for roles and skills that will generate important educational and training needs at a general societal level (Ison et al. 2007). Here, we have to restart from scratch. Social norms influence the 
acceptability of environmental policies principally when joint with coerciveness of environmental policies (de Groot and Schuitema 2012). The lack of a specific legislation on the soil issue in this case is particularly evident and relevant. It is urged that multi-scale measures promoting the conservation of high-quality agricultural land and reducing the environmental impact of soil sealing should be incorporated into a 'polycentric' regional planning strategy (Faludi 2005; Korthals Altes and Tambach 2008) avoiding excessive settlement dispersion (Salvati et al. 2013).

\section{Conclusions: lessons from Mappano}

High levels of satisfaction and perceived quality of life could be independent of the objective life conditions (Pol et al. 2002). In conclusion, we arrive at three considerations. The first is that an administrative event, such as the creation of a new small municipality, happens without any consideration of land and soil risks: no debate, no political conditions, and no evaluations have been a part of that process. The second is that the birth of Mappano allows us to understand that our cultural perceptions about landscape risks are very, very low or even absent and so there is no cultural force able to oppose that decision. This is a great defeat regarding not only Mappano or the Region of Piedmont or Italy but the whole mentality of our urban culture in Europe, which needs to be changed. The third regards the remains of our urban culture and civic attitude. We need to enforce issues dealing with environment, landscape and soil from a cultural point of view. Our citizens, our politicians and our technicians have too weak an idea of land and soil, which prevents them from finding sustainable alternatives. The time to invest in culture is now, as we all know that culture can be the best preventive medicine. Furthermore, the development of a linkage between urban and rural construction land management should be a reasonable and effective means for sustainable land development (Liu et al. 2015).

Nevertheless, the case of Mappano has a general significance. In fact Mappano has been firstly possible to an over simplification of the post-modern idea of local identity that seems (1) to be an undeniable, primary and nonnegotiable element of present time and (2) to overlay to the despotic idea of natural resources as more similar to commodities than to commons. Therefore, the satisfaction of local identity often means to build new barrier as a comfort zone where it is guaranteed, first, the right to decide independently by what and by the effects versus environmental resources and communities beyond the border. A sort of systematic dissociation between people and the surrounding landscape, people and the surrounding people. Policy and urban planning did not do anything effective to oppose, demonstrating to be weak disciplines, unable to affirm environmental reasons. This is a strong lesson asking us to be more able to define cultural and practical tools to let people know about the benefits to consider natural resources as a 'plus' and not a 'minus'. We must renovate our arguments and the way to communicate them. Landscape fragmentation goes on being perceived as non-problem or, even, as a pillar of local identity wiping out all that issues that imply an over-boundary glance, suggesting to group and not to scatter.

Finally, we can get a further closing lesson thanks to a recent Italian law, L. 56/2014 known as Delrio law, by which groupings and fusions amid municipalities are foreseen, although in a volunteer way. Despite that law, whose approval process started just a couple years before, Mappano might born contradicting the law spirit itself. This suggests us that tools to avoid fragmentation must be more robust and, probably, mandatory or strongly convincing, working onto three parallel sides (for smallmedium municipalities): encouraging the groupings with special subsidies, stopping or dropping ordinary subsidies to municipalities that can merge but refute to do it and discouraging new fragmentations applying new taxes, if happens.

But the municipality fusion is a problematic issue as long as cultural and political ripeness have been formed. In the meantime a good 'third way' could be to gather competences from many to one, especially environmental ones, as land use that implies soil protection, from biodiversity to water management, that do not respect administrative borders, by nature, and need a wider glance.

\section{Authors' contributions}

RS made substantial contributions to conception and design. PP and RS both made acquisition, analysis and interpretation of all data. PP and RS participated in drafting the article and revising it critically for important intellectual content. Both authors read and approved the final manuscript.

\section{Author details}

${ }^{1}$ Politecnico di Milano, Milan, Italy. ${ }^{2}$ Università degli Studi di Palermo, Palermo, Italy.

\section{Competing interests}

The authors declare that they have no competing interests.

Received: 14 March 2016 Accepted: 3 May 2016

Published online: 20 May 2016

\footnotetext{
References

Bouma J, Droogers P (2007) Translating soil science into environmental policy: a case study on implementing the EU soil protection strategy in The Netherlands. Environ Sci Policy 10:454-463

Bray Z (2002) Creating a unified urban space astride a state frontier: opportunities and challenges. The case of Bidasoa-Txingudi, Basque Country. Die Erde 133:55-67

Brubaker R, Cooper F (2000) Beyond 'identity'. Theory Soc 29:1-47
} 
Burchell RW, Lowenstein G, Dolphin WR, Galley CC, Downs A, Seskin S, Gray Still K, Moore T (2002) Costs of Sprawl—2000. National Academy Press, Washington

de Groot JIM, Schuitema G (2012) How to make the unpopular popular? Policy characteristics, social norms and the acceptability of environmental policies. Environ Sci Policy 19-20:100-107

De Matteis G, Ferlaino F (2003) Socio-economic and geographical analysis of Mappano. Istituto Ricerche Economico Sociali Piemonte, Torino, IT EU, p 113 (in Italian)

Deal B, Schunk D (2004) Spatial dynamic modeling and urban land use transformation: a simulation approach to assessing the costs of urban sprawl. Ecol Econ 51:79-95

Del Biaggio C (2014) Investigating regional identities within the pan-Alpine governance system: the presence or absence of identification with a "community of problems" among local political actors. Environ Sci Policy 49:45-56

Desouza KC, Flanery TH (2013) Designing, planning, and managing resilient cities: a conceptual framework. Cities 35:89-99

Dessie Y, Schubert U, Wurzinger M, Hauser M (2013) The role of institutions and social learning in soil conservation innovations: implications for policy and practice. Environ Sci Policy 27:21-31

Di Simine D, Pileri P, Ronchi S (2013) Land take and environmental effects: how to reshape our urban plans. II Progetto Sostenibile 33:14-23 (in Italian)

Dubiez E, Yamba Yamba T, Mvolo B, Freycon V (2014) Local perceptions of soils and their gradual transformation into savannah in batandu village lands in the democratic Republic of Congo. Bois For Trop 68:19-29

Faludi AKF (2005) Polycentric territorial cohesion policy. Town Plan Rev 76:107-118

Ferlaino F, Mazzoccoli A, Mela A (1994) Periferie delle città e sistemi urbani: alternative per la riqualificazione della città futura. In: Gasparini A, Logan JR, Mansurov V (eds) Riqualificazione e Hinterland delle Grandi Città. Franco Angeli, Milano, IT EU, p 27-68 (in Italian)

Finotto F, Paludi G (2012) Monitoraggio del Consumo di Suolo in Piemonte. Regione Piemonte, Torino, IT EU, p 148 (in Italian)

Gardi C, Panagos P, Van Liedekerke M, Bosco C, de Brogniez D (2014) Land take and food security: assessment of land take on the agricultural production in Europe. J Environ Plan Manage 58:898-912

Gerland P, Raftery AE, Ševčíková H, Li N, Gu D, Spoorenberg T, Alkema L, Fosdick BK, Chunn J, Lalic N, Bay G, Buettner T, Heilig GK, Wilmoth J (2014) World population stabilization unlikely this century. Science 346:234-237

Haase D, Nuissl H (2007) Does urban sprawl drive changes in the water balance and policy? The case of Leipzig (Germany) 1870-2003. Landsc Urban Plan 80:1-13

Häkli J (2001) The politics of belonging: complexities of identity in the Catalan borderlands. Geogr Ann 83:111-119

Ison R, Röling N, Watson D (2007) Challenges to science and society in the sustainable management and use of water: investigating the role of social learning. Environ Sci Policy 10:499-511

Kaplan R, Kaplan S, Austin ME (2008) Factors shaping local land use decisions: citizen planners' perceptions and challenges. Environ Behav 40:46-71

Kim BF, Poulsen MN, Margulies JD et al (2014) Urban community gardeners' knowledge and perceptions of soil contaminant risks. PLoS One 9:e87913

Korthals Altes WK, Tambach M (2008) Municipal strategies for introducing housing on industrial estates as part of compact-city policies in the Netherlands. Cities 25:218-229

Liu T, Liu H, Qi Y (2015) Construction land expansion and cultivated land protection in urbanizing China: insights from national land surveys, 1996-2006. Habitat International 46:13-22
Malucelli F, Certini G, Scalenghe R (2014) Soil is brown gold in the EmiliaRomagna region, Italy. Land Use Policy 39:350-357

Munafò M, Salvati L, Zitti M (2013) Estimating soil sealing rate at national level-Italy as a case study. Ecol Ind 26:137-140

Nuissl H, Schroeter-Schlaack C (2009) On the economic approach to the containment of land consumption. Environ Sci Policy 12:270-280

Pileri P (2015) Che cosa c'è sotto. II suolo, i suoi segreti, le ragioni per difenderlo, Altreconomia editore, p 160 (in Italian)

Pileri P, Granata E (2012) Amor Loci-Suolo, Ambiente, Cultura Civile. Raffaello Cortina Editore, Milano, IT EU, p 273 (in Italian)

Pol E, Moreno E, Guàrdia J, íniquez L (2002) Identity, quality of life, and sustainability in an urban suburb of Barcelona: adjustment to the city-identitysustainability network structural model. Environ Behav 34:67-80

Power A (2001) Social exclusion and urban sprawl: is the rescue of cities possible? Reg Stud 35:731-742

Provincia Torino (2012) Anno 2012: a Che Punto il Consumo del Suolo? Provincia di Torino, IT EU. http://www.provincia.torino.gov.t//speciali/2012/ consumo territorio/(in Italian)

Quansah C, Drechsel P, Yirenkyi BB, Asante-Mensah S (2001) Farmers' perceptions and management of soil organic matter-a case study from West Africa. Nutr Cycl Agroecosyst 61:205-213

Salvati L (2015) Monitoring high-quality soil consumption driven by urban pressure in a growing city (Rome, Italy). Cities 31:349-356

Salvati L, Zitti M, Sateriano A (2013) Changes in city vertical profile as an indicator of sprawl: evidence from a Mediterranean urban region. Habitat Int 38:119-125

Scalenghe R, Ajmone Marsan F (2009) The anthropogenic sealing of soils in urban areas. Landsc Urban Plan 90:1-10

Scalenghe R, Fasciani G (2008) Soil heavy metals patterns in the Torino Olympic Winter Games venue (EU). Soil Sedim Contam 17:205-220

Schnell SM (2013) Deliberate identities: becoming local in America in a global age. J Cult Geogr 30:55-89

Thomas RJ, Akhtar-Schuster M, Stringer LC, Marques MJ, Escadafal R, Abraham E, Enne G (2012) Fertile ground? Options for a science-policy platform for land. Environ Sci Policy 16:122-135

Vandermoere F (2006) The process of soil excavation in a community: sitespecific determinants of stress perception. Environ Behav 38:715-739

Vandermoere F (2008) Hazard perception, risk perception, and the need for decontamination by residents exposed to soil pollution: the role of sustainability and the limits of expert knowledge. Risk Anal 28:387-398

Vaz E, Nijkamp P (2014) Gravitational forces in the spatial impacts of urban sprawl: an investigation of the region of Veneto, Italy. Habitat Int 45:99-105

Wells NM, Ashdown SP, Davies EHS, Cowett FD, Yang Y (2007) Environment, design, and obesity: opportunities for interdisciplinary collaborative research. Environ Behav 39:6-33

Yang X, Lo CP (2002) Using a time series of satellite imagery to detect land use and land cover changes in the Atlanta, Georgia metropolitan area. Int J Remote Sens 23:1775-1798

\section{Submit your manuscript to a SpringerOpen ${ }^{\circ}$ journal and benefit from:}

- Convenient online submission

- Rigorous peer review

- Immediate publication on acceptance

- Open access: articles freely available online

- High visibility within the field

- Retaining the copyright to your article

Submit your next manuscript at $\boldsymbol{\nabla}$ springeropen.com 